\title{
ATRIBUTOS DE UM LATOSSOLO E COMPONENTES PRODUTIVOS DA SOJA: UMA ABORDAGEM LINEAR E GEOESTATÍSTICA
}

\author{
Lenon Henrique Lovera* \\ Rafael Montanari** \\ Elizeu de Souza Lima*** \\ Alan Rodrigo Panosso***** \\ Mariele Squizato***** \\ Ingrid Nehmi de Oliveira*
}

RESUMO: O estudo dos atributos do solo e componentes de produção da planta utilizando a geoestatística, e a consequente geração de mapas de krigagem, podem ser utilizadas na otimização de fertilizantes e, assim, reduzir a produção. O objetivo deste experimento foi avaliar a dependência espacial dos atributos resistência a penetração (RP), teor de água (TA), densidade do solo (DS), porosidade total (PT), Areia (Are), Argila (Arg), Silte (Sil), fósforo (P), matéria orgânica (MO), potencial Hidrogeniônico $(\mathrm{pH})$, potássio $(\mathrm{K})$ e saturação por bases $(\mathrm{V})$ de um Latossolo Vermelho Distroférrico em duas profundidades (0,00-0,10 m e 0,10-0,20 m), com os componentes produtivos número de vagens por planta (NVP), número de grãos por vagem (NGV), número de grãos por planta (NGP), massa de 100 grãos (MCG) e produtividade de grãos (PG) da soja (Glycine max L.) cultivada em plantio direto no ano agrícola de 2013/2014, no município de Selvíria (MS). Foi instalada uma rede amostral, para a coleta de dados do solo e das plantas, com 100 pontos amostrais distribuídos aletoriamente, em uma área de $7.980 \mathrm{~m}^{2}$. As maiores variabilidades dos atributos analisadas pelo coeficiente de variação ocorreram na camada de 0,00-0,10 $\mathrm{m}$ do solo. Alguns dos atributos de solo e planta pesquisados apresentaram dependência espacial, sendo possível mapear a área em estudo. Os valores dos alcances recomendados para os atributos pesquisados deverão estar compreendidos entre 9,9 e $91,8 \mathrm{~m}$.

PALAVRAS-CHAVE: Agricultura de precisão; Manejo do solo; Mapas de krigagem.

\footnotetext{
Doutorando da Faculdade de Engenharia Agrícola. Unicamp. Brasil. E-mail: lhlovera@gmail.com

** Docente adjunto do Departamento de Fitossanidade, Engenharia Rural e Solos - Unesp de Ilha Solteira, Brasil.

*** Doutorando da Faculdade de Engenharia Agrícola. Unicamp. Brasil.

**** Docente Assistente Doutor do Departamento de Ciências Exatas, Unesp Jaboticabal. Brasil.

${ }^{* * * * *}$ Acadêmico de graduação em Engenharia Agronômica. Unesp de Ilha Solteira. Brasil.

${ }^{* * * * * *}$ Doutoranda da Faculdade de Engenharia Agrícola, Unicamp. Brasil.
} 


\section{ATTRIBUTES OF LATOSOL AND SOYBEAN PRODUCTION COMPONENTS: A LINEAR AND GEO-STATISTIC APPROACH}

ABSTRACT: Studies on soil qualities and components of plant production by Geostatistics and the generation of Kriging maps may be employed for the improvement of fertilizers and reduce production. Current assay evaluates the spatial dependence of attributes resistant to penetration (RP), water rate (WR), soil density (SD), total porosity (TP), sand (S), clay $(\mathrm{C})$, silt $(\mathrm{ST})$, phosphorus $(\mathrm{P})$, organic matter $(\mathrm{OM})$, hydrogenionic potential $(\mathrm{pH})$, potassium $(\mathrm{K})$ and base saturation $(\mathrm{V})$ of a dystrophic red latosol at depths $(0.00-0.10 \mathrm{~m}$ and $0.10-0.20 \mathrm{~m})$, with production components number of pods per plant (NPP), number of grains per pod (NGP), number of grains per plant (NGP), mass of 100 grains (MCG) and grain productivity (GP) of soybean (Glycine max L.), cultivated at zero tillage in 2013/2014, in Selvíria MS Brazil. A sample network was established for data collection of soil and plants, with 100 randomized sampling points within an area of $7,980 \mathrm{~m}^{2}$. Greatest variability of attributes analyzed by the coefficient of variance occurred at soil depth $0.00-0.10 \mathrm{~m}$. Several soil and plant attributes had spatial dependence, with a possibility of mapping the area under analysis. Rates recommended for researched attributes were between 9.9 and $91.8 \mathrm{~m}$.

KEY WORDS: Precision agriculture; Soil management; Kriging maps.

\section{INTRODUÇÃO}

A cultura da soja tem sido uma das atividades agrícolas que expressa os maiores crescimentos em termos de produção (FREITAS; MENDONÇA, 2016), tornando-se de grande importância para a economia mundial. Alguns fatores como a grande demanda da soja pelo mercado internacional, a consolidação desta cultura como importante fonte de proteína e o grande desenvolvimento de tecnologias, intensificaram a expansão agrícola da mesma no Brasil (EMBRAPA, 2011). Dentro desse vasto mercado de oferta e demanda da soja, o Brasil é um dos maiores produtores, ficando atrás somente dos EUA. Na safra 2014/2015, a cultura ocupou uma área de 31,57 milhões de hectares, com produção de aproximadamente 95 milhões de toneladas e produtividade média de $3.009 \mathrm{~kg}$ por hectare (CONAB, 2015). Devido à grande importância da soja na economia brasileira, as buscas por práticas sustentáveis e preservação do meio ambiente são cada vez mais necessárias, otimizando 
a produção desta cultura. Existem alguns aspectos que são fundamentais para 0 sucesso na produção, sendo eles: melhoramento; manutenção e gerenciamento da qualidade do solo; servindo para diminuir perdas e custos, elevar a produtividade e aumentar a qualidade dos produtos (MONTANARI et al., 2012).

Sabe-se que a qualidade do solo é fortemente influenciada pelos atributos físicos, químicos e biológicos; desta forma, estudos que busquem esclarecer relações desses atributos com os componentes produtivos da cultura são de fundamental importância no momento da tomada de decisão quanto às práticas de manejo do solo (MONTANARI et al., 2015). Estes atributos do solo são indicadores da qualidade deste, utilizados para quantificar sua degradação, modificações na estrutura, porosidade, agregação e densidade do solo, bem como na infiltração e disponibilidade de água, fornecendo informações para o manejo de um sistema de produção (REYNOLDS et al., 2008).

Os atributos do solo apresentam dependência espacial, ou seja, os valores de uma variável são autocorrelacionados no campo (SANTOS et al., 2015). Nesse contexto, são necessárias técnicas que incorporem as coordenadas geográficas dos pontos estudados nos trabalhos da área. Portanto, o uso da geoestatística pode auxiliar na procura de alternativas de manejo que propiciem minimizar o efeito da variabilidade espacial dos atributos físicos e químicos do solo sobre os cultivos. Constitui-se uma ferramenta útil para analisar as variáveis dependentes, proporcionando a confecção de mapas de krigagem para cada atributo pesquisado e possibilitando uma nova perspectiva de avaliação dos atributos físicos e químicos do solo (CASTRIGNANÒ et al., 2000; DALCHIAVON et al., 2011). Diante do exposto, o objetivou-se caracterizar a dependência espacial dos atributos do solo e a sua relação com os componentes de produção e produtividade da cultura da soja em um Latossolo Vermelho Distroférrico na região de Selvíria (MS).

\section{MATERIAL E MÉTODOS}

O trabalho foi conduzido na área experimental da Fazenda de Ensino, Pesquisa e Extensão da Faculdade de Engenharia de Ilha Solteira (FEIS/UNESP), localizada no município de Selvíria (MS), entre as latitudes de 20¹8'05"S e 20¹8'28"S e as longitudes de 52 39'02"W e 5240'28”W, e $360 \mathrm{~m}$ acima do nível do mar, no ano agrícola 2013/14. A precipitação pluvial média anual da área é de $1.300 \mathrm{~mm}$, 
enquanto que a temperatura média é de $23,7^{\circ} \mathrm{C}$. O tipo climático é Aw, segundo Köppen, caracterizado como tropical úmido com estação chuvosa no verão e seca no inverno (Figura 1).

A malha experimental foi instalada em um Latossolo Vermelho Distroférrico típico argiloso, com declive homogêneo de $0,025 \mathrm{~m} \mathrm{~m}^{-1}$ (EMBRAPA, 2013), sendo uma das classes de maior ocorrência no Brasil. O solo no qual foi estabelecida a pesquisa vinha sendo utilizado com a sucessão das culturas do milho ou soja (verão) e feijão ou milho (inverno) há 28 anos. Nos primeiros 15 anos foi realizado o preparo convencional para condução das culturas mencionadas e, nos últimos 13 anos, adotou-se o plantio direto, não havendo nenhuma adubação de superfície, apenas no sulco de semeadura.

O espaçamento entrelinhas da cultura da soja foi de $0,45 \mathrm{~m}$, com 16 plantas por metro na linha de semeadura, sendo semeada em 07/11/2013 utilizando a cultivar valiosa. Na adubação de semeadura foi aplicado $400 \mathrm{~kg} \mathrm{ha}^{-1}$ da formulação 08-28-16 (N-P-K respectivamente). A determinação dos pontos de coleta de amostras de solo e planta foi feita com auxílio de malha amostral; para isso, foi utilizado um nível ótico comum, efetuando-se o estaqueamento global da malha experimental, contendo 100 pontos de forma a cobrir a área escolhida para amostragem (7.980 $\left.\mathrm{m}^{2}\right)$.

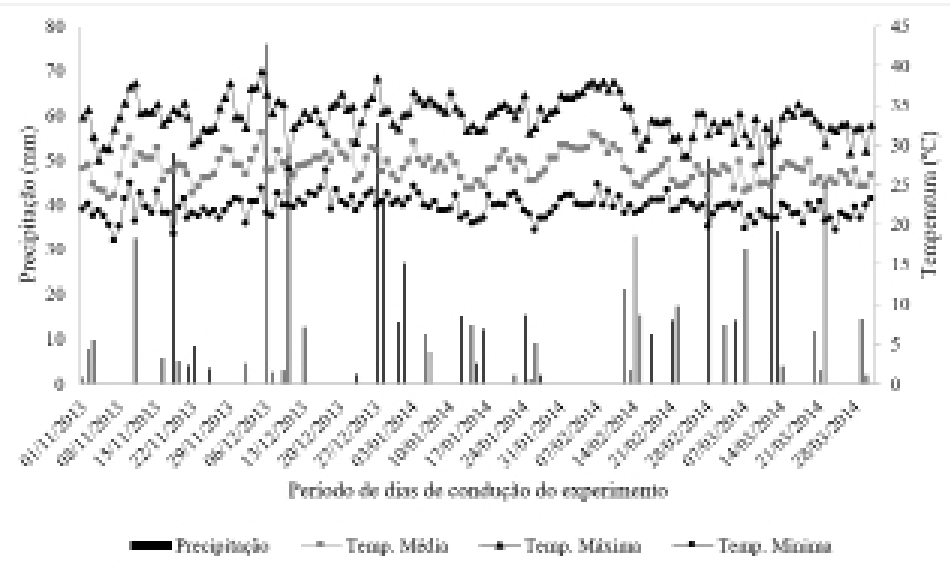

Figura 1. Termopluviometria da Precipitação pluvial e temperatura do ar durante o período de cultivo da soja (novembro/2013 a março/2014), Selvíria (MS) 
Os atributos pesquisados do solo foram: a) resistência mecânica à penetração (RP), b) teor de água (TA), c) densidade do solo (DS), d) porosidade total (PT), e) Areia (Are), f) Argila (Arg), g) Silte (Sil), h) fósforo (P), i) matéria orgânica $(\mathrm{MO}), \mathrm{j})$ potencial hidrogeniônico $(\mathrm{pH}), \mathrm{k}$ ) potássio $(\mathrm{K})$ e l) saturação por bases (V). As coletas foram realizadas em janeiro de 2014 em duas profundidades, a saber: a) 0,00-0,10 m (C1), e b) 0,10-0,20 m (C2), as colheitas foram realizadas no período em que as plantas estavam em seu estádio de florescimento. Todas as análises foram processadas conforme metodologias de Stolf (1991), Raij et al. (2001) e Embrapa (2011).

Os componentes da soja avaliados foram: a) número de vagens por planta (NVP), b) número de grãos por vagem (NGV), c) número de grãos por planta (NGP), d) massa de cem grãos (MCG) e e) produtividade de grãos (PG), com os valores extrapolados e representados em $\mathrm{kg} \mathrm{ha}^{-1}$. A área representativa dessa coleta foi de $3,24 \mathrm{~m}^{2}$, com quatro linhas de plantas $(1,80 \times 1,80 \mathrm{~m})$, contendo 100 pontos amostrais. A colheita da cultura da soja consistiu do arranquio manual das plantas, efetuada aos 130 dias após a emergência. Seguidamente, o material de cada ponto amostral foi colocado para secagem em um terreiro sob o sol e a trilha efetuada com debulhadora mecânica, separando os grãos da planta.

Para cada atributo do solo e componente da soja estudado foi efetuada a análise descritiva auxiliada pela estatística clássica, utilizando-se o SAS (SAS versão 9.3, SAS Institute, Cary, NC, EUA).

Para cada atributo foi analisada a dependência espacial pelo ajuste do semivariograma, com bases nos pressupostos de estacionariedade da hipótese intrínseca, usando o software geoestatístico $\mathrm{GS}^{+}$(2004) $\left(\mathrm{GS}^{+}\right.$Geostatistics for Environmental Sciences, versão 9.0, Gamma Design Software, Plainwell, MI, EUA). Foram ajustados semivariogramas simples a todos os atributos estudados de solo e planta. A decisão final do modelo que representou o ajuste foi realizada pela validação cruzada, assim como para a definição do tamanho da vizinhança que proporcionou a melhor malha de krigagem. Para cada atributo foram estimados o efeito pepita $\left(\mathrm{C}_{\mathrm{o}}\right)$, o alcance $\left(\mathrm{A}_{\mathrm{o}}\right)$, coeficiente de determinação $\left(\mathrm{r}^{2}\right)$, avaliador de dependência espacial $(\mathrm{ADE})$ e o patamar $\left(\mathrm{C}_{\mathrm{o}}+\mathrm{C}\right)$. 


\section{RESULTADO}

A variabilidade de um atributo pode ser classificada segundo a magnitude de seu coeficiente de variação (CV), se o CV for $\leq 10 \%$ é considerado baixo, $10 \%$ $<\mathrm{CV} \leq 20 \%$ - médio, $20 \%<\mathrm{CV} \leq 30 \%$ - alto e CV $>30 \%$ - muito alto (PIMENTEL-GOMES; GARCIA, 2002). Em se tratando dos atributos da planta, a produtividade de grãos da soja (PG) apresentou variabilidade muito alta, com CV de 39\% (Quadro I). Já o NVP e o NGP apresentaram alta variabilidade com CV's de 23,7 e 25,5\%, respectivamente, enquanto o NGV e a MCG observaram baixa variabilidade, com CV's de 6,7 e $8,8 \%$ respectivamente (Tabela 1 ).

Avaliando os atributos físicos do solo (Quadro I), as variabilidades da TA, da DS, da PT, da Are, Arg e pH nas duas camadas de solo estudadas foram baixas, com CV's entre 3,3 e 8,9\% (Quadro I). Enquanto que RP obteve coeficiente muito alto (RP1) e alto (RP2). Em relação ao teor de silte (Sil) e o teor de matéria orgânica do solo (MO), todos apresentaram variabilidade de média a baixa em ambas as profundidades (Tabela 1), com CV's entre 9,1 e 12,3\%.

Tabela 1. Estatística descritiva inicial dos componentes produtivos e produtividade da soja e atributos físicos e químicos de um Latossolo Vermelho Distroférrico, Selvíria (MS)

\begin{tabular}{|c|c|c|c|c|c|c|c|c|c|c|}
\hline \multirow{2}{*}{ Atributos $^{(a)}$} & \multirow{2}{*}{ Média } & \multirow{2}{*}{ Mediana } & \multirow[b]{2}{*}{ Mín. } & \multirow[b]{2}{*}{ Máx. } & \multirow{2}{*}{$\begin{array}{l}\text { Desvio } \\
\text { Padrão }\end{array}$} & \multicolumn{3}{|c|}{ Coeficientes } & \multicolumn{2}{|c|}{$\begin{array}{l}\text { Probabilida- } \\
\text { de do teste }^{(b)}\end{array}$} \\
\hline & & & & & & $\operatorname{Var}(\%)$ & Curt. & Ass. & $\operatorname{Pr}<w$ & DF \\
\hline \multicolumn{11}{|c|}{ Atributos da planta } \\
\hline PG $\left(k g h^{-1}\right)$ & 1214,8 & 1250,0 & 169,8 & 2361,1 & 473,7 & 39,0 & $-0,281$ & $-0,160$ & 0,268 & NO \\
\hline NVP & 30,5 & 29,5 & 10,3 & 51,0 & 7,235 & 23,7 & 0,555 & 0,517 & 0,029 & $\mathrm{TN}$ \\
\hline NGV & 1,9 & 1,9 & 1,7 & 2,2 & 0,129 & 6,7 & - & - & - & IN \\
\hline NGP & 59,1 & 57,4 & 20,7 & 100,9 & 14,505 & 25,5 & 0,363 & 0,468 & 0,076 & NO \\
\hline $\operatorname{MCG}(\mathrm{g})$ & 15,9 & 15,8 & 11,4 & 19,1 & 1,404 & 8,8 & 0,084 & $-0,298$ & 0,594 & NO \\
\hline \multicolumn{11}{|c|}{ Atributos físicos do solo } \\
\hline RP1 (MPa) & 6,036 & 5,795 & 1,674 & 13,091 & 2,442 & 40,4 & - & - & - & IN \\
\hline RP2 (MPa) & 12,256 & 12,458 & 5,748 & 20,152 & 3,091 & 25,2 & -0.440 & $-0,082$ & 0,527 & NO \\
\hline TA1 ( $\left.\mathrm{kg} \mathrm{kg}^{-1}\right)$ & 0,156 & 0,157 & 0,131 & 0,181 & 0,009 & 5,7 & 0,936 & $-0,317$ & 0,021 & $\mathrm{TN}$ \\
\hline TA2 $\left(\mathrm{kg} \mathrm{kg}^{-1}\right)$ & 0,162 & 0,162 & 0,139 & 0,183 & 0,007 & 4,6 & 1,843 & $-0,179$ & 0,004 & $\mathrm{TN}$ \\
\hline
\end{tabular}




\begin{tabular}{|c|c|c|c|c|c|c|c|c|c|c|}
\hline \multirow[t]{2}{*}{ Atributos $^{(a)}$} & \multirow[t]{2}{*}{ Média } & \multirow[t]{2}{*}{ Mediana } & \multirow[b]{2}{*}{ Mín. } & \multirow[b]{2}{*}{ Máx. } & \multirow{2}{*}{$\begin{array}{l}\text { Desvio } \\
\text { Padrão }\end{array}$} & \multicolumn{3}{|c|}{ Coeficientes } & \multicolumn{2}{|c|}{$\begin{array}{l}\text { Probabilida- } \\
\text { de do teste }^{(\mathrm{b})}\end{array}$} \\
\hline & & & & & & $\operatorname{Var}(\%)$ & Curt. & Ass. & $\operatorname{Pr}<w$ & DF \\
\hline DS2 $\left(\mathrm{kg} \mathrm{dm}^{-3}\right)$ & 1,411 & 1,418 & 1,228 & 1,555 & 0,066 & 4,7 & 0,114 & $-0,390$ & 0,180 & NO \\
\hline PT1 $\left(\mathrm{m}^{3} \mathrm{~m}^{-3}\right)$ & 0,489 & 0,490 & 0,408 & 0,589 & 0,043 & 8,9 & $-0,689$ & 0,184 & 0,203 & NO \\
\hline PT2 $\left(\mathrm{m}^{3} \mathrm{~m}^{-3}\right)$ & 0,467 & 0,460 & 0,396 & 0,548 & 0,032 & 6,9 & $-0,345$ & 0,392 & 0,051 & NO \\
\hline $\operatorname{Are1}\left(\mathrm{g} \mathrm{kg}^{-1}\right)$ & 357,7 & 357,0 & 303,0 & 426,0 & 23,020 & 6,4 & 0,259 & 0,180 & 0,655 & NO \\
\hline $\operatorname{Are} 2\left(\mathrm{~g} \mathrm{~kg}^{-1}\right)$ & 353,4 & 355,0 & 286,0 & 399,0 & 19,988 & 5,6 & 0,688 & $-0,448$ & 0,095 & NO \\
\hline $\operatorname{Arg} 1\left(\mathrm{~g} \mathrm{~kg}^{-1}\right)$ & 498,1 & 499,0 & 455,0 & 542,0 & 16,373 & 3,3 & $-0,199$ & $-0,027$ & 0,892 & NO \\
\hline $\operatorname{Arg} 2\left(\mathrm{~g} \mathrm{~kg}^{-1}\right)$ & 503,3 & 504,0 & 458,0 & 563,0 & 18,746 & 3,7 & 0,321 & 0,143 & 0,812 & NO \\
\hline Sil1 $\left(\mathrm{g} \mathrm{kg}^{-1}\right)$ & 144,0 & 145,0 & 94,0 & 198,0 & 15,851 & 11,0 & 1,187 & 0,111 & 0,349 & NO \\
\hline Sil2 $\left(\mathrm{g} \mathrm{kg}^{-1}\right)$ & 143,4 & 143,0 & 112,0 & 188,0 & 13,014 & 9,1 & 1,128 & 0,272 & 0,141 & NO \\
\hline \multicolumn{11}{|c|}{ Atributos químicos do solo } \\
\hline P1 $\left(\mathrm{mg} \mathrm{dm}^{-3}\right)$ & 18,1 & 18,0 & 9,0 & 30,0 & 4,038 & 22,3 & 0,197 & 0,604 & 0,012 & $\mathrm{TN}$ \\
\hline $\mathbf{P} 2\left(\mathrm{mg} \mathrm{dm}^{-3}\right)$ & 16,2 & 15,0 & 5,0 & 44,0 & 7,318 & 45,0 & - & - & - & IN \\
\hline $\operatorname{MO1}\left(\mathrm{g} \mathrm{dm}^{-3}\right)$ & 17,5 & 17,0 & 12,0 & 24,0 & 2,153 & 12,3 & - & - & - & IN \\
\hline MO2 $\left(\mathrm{g} \mathrm{dm}^{-3}\right)$ & 16,6 & 16,5 & 14,0 & 20,0 & 1,640 & 9,9 & - & - & - & IN \\
\hline pH1 $\left(\mathrm{CaCl}_{2}\right)$ & 4,5 & 4,5 & 4,2 & 5,0 & 0,161 & 3,5 & - & - & - & IN \\
\hline $\mathrm{pH} 2\left(\mathrm{CaCl}_{2}\right)$ & 4,8 & 4,9 & 4,3 & 5,6 & 0,274 & 5,6 & - & - & - & IN \\
\hline $\begin{array}{c}\mathrm{K} 1 \mathrm{(mmol}_{\mathrm{c}} \\
\left.\mathrm{dm}^{-3}\right)\end{array}$ & 1,6 & 1,3 & 0,5 & 4,1 & 0,911 & 55,9 & - & - & - & IN \\
\hline $\begin{array}{c}\mathrm{K} 2\left(\mathrm{mmol}_{\mathrm{c}}\right. \\
\left.\mathrm{dm}^{-3}\right)\end{array}$ & 0,8 & 0,7 & 0,2 & 2,0 & 0,424 & 50,8 & - & - & - & IN \\
\hline V1 (\%) & 34,6 & 34,0 & 18,0 & 54,0 & 7,143 & 20,6 & $-0,035$ & 0,218 & 0,803 & NO \\
\hline V2 (\%) & 34,4 & 33,5 & 17,0 & 50,0 & 7,805 & 22,7 & $-0,804$ & 0,259 & 0,018 & $\mathrm{TN}$ \\
\hline
\end{tabular}

(a) $\mathrm{PG}=$ produtividade de grãos de soja; $\mathrm{NVP}=$ número de vagens por planta; $\mathrm{NGV}=$ número de grãos por vagem; NGP = número de grãos por planta; $\mathrm{MCG}=$ massa de cem grãos; RP, TA, DS, PT, Are, Arg, Sil, P, MO, pH, K e V \% de 1 a 2, são respectivamente a resistência à penetração, teor de água, densidade do solo, porosidade total, areia, argila, silte, fósforo, matéria orgânica, potencial hidrogeniônico, potássio e saturação por bases, coletados nas camadas de 0,00-0,10 m e 0,10-0,20 m do solo; (b) DF = distribuição de frequência, sendo NO, TN e IN respectivamente do tipo normal, tendendo a normal e indeterminada; (c) Min = mínima e Max = máxima; Coeficientes: $\operatorname{Var}=$ variação, curt $=$ curtose e ass $=$ assimetria.

A partir dos dados dos atributos químicos do solo (Tabela 1), o teor de fósforo disponível do solo (P) apresentou alta variabilidade na camada $\mathrm{C} 1$ e muito alta variabilidade na camada C2, com CV's de 22,3 e 45,0\%, respectivamente (Tabela 1). Por sua vez, o teor potássio do solo $(\mathrm{K})$ apresentou variabilidade muito alta em ambas as profundidades, 55,9 e 50,8\%, para as camadas de $\mathrm{C} 1$ e $\mathrm{C} 2$, respectivamente. 
Quando uma variável estatística qualquer possuir distribuição de frequência normal, a medida de tendência central mais adequada para representá-la deve ser a média. Em contrapartida, será pela mediana, ou pela média geométrica, caso possua distribuição de frequência lognormal (SPIEGEL, 1985). Portanto, os atributos produtividade de grãos da soja (PG), número de grãos por planta (NGP) e massa de cem grãos (MCG) apresentaram distribuição de frequência do tipo normal, com coeficientes de assimetria positivo de 0,468 para NGP, e negativos de $-0,160$ e $-0,298$ para PG e MCG, respectivamente (Quadro I). Por outro lado, os coeficientes de curtose positivos para NGP e MCG foram de 0,363 e 0,084, respectivamente, e negativo de -0,281 para PG. A hipótese de normalidade dos dados de cada variável foi averiguada por meio do teste de normalidade de Shapiro e Wilk (1965) ao nível de 5\% de significância (Quadro I), assim, independentemente de tais coeficientes, o teste de normalidade foi não significativo para esses atributos, indicando que os dados apresentam distribuição normal $(\mathrm{p}>0,05)$. Porém, o número de vagens por planta (NVP) e número de grãos por vagem (NGV) apresentaram distribuição de frequência do tipo tendendo a normal e indeterminado, respectivamente, com valores de probabilidade associada à estatística do teste de 0,029, respectivamente.

Os atributos que apresentaram valores não significativos $(\mathrm{p}>0,05)$ para 0 teste de normalidade de Shapiro e Wilk foram considerados normais: RP2, DS1, DS2, PT1, PT2, Are1, Are2, Arg1, Arg2, Sil1, Sil2 e V1, portanto, as respectivas medidas de tendência central foram representadas pelas suas respectivas médias, com coeficientes de assimetria positiva entre $-0,448$ e 0,392 . Por sua vez, os coeficientes de curtose variaram de -0,689 e 1,187 (Tabela 1). Os valores médios do P, MO, pH, K e V sofreram diminuição em profundidade, com exceção do pH, que ocorreu um aumento em profundidade.

No Quadro II estão apresentados os parâmetros dos semivariogramas simples ajustados para a produtividade da soja e de atributos físicos e químicos. Assim, ficou atestado que os atributos NGV, NGP, RP1, RP2, TA1, TA2, DS1, DP1, DP2, PT1, PT2, Arg1, Sil1, P1, P2, K2 e V1 apresentaram efeito pepita puro e os demais atributos apresentaram dependência espacial. A ocorrência do efeito pepita puro é um indicativo de que esses atributos são espacialmente independentes, apresentam distribuição aleatória ou de que o espaçamento da malha amostral é maior que o necessário para revelar a dependência espacial (MACHADO et al., 2007). No tocante ao desempenho dos semivariogramas, a relação decrescente deles, analisada pela grandeza do coeficiente de determinação espacial $\left(\mathrm{r}^{2}\right)$, foi que a Arg2 e Are2, foram os atributos de melhor ajuste semivariográfico, que tiveram elevados coeficientes de determinação espacial. 


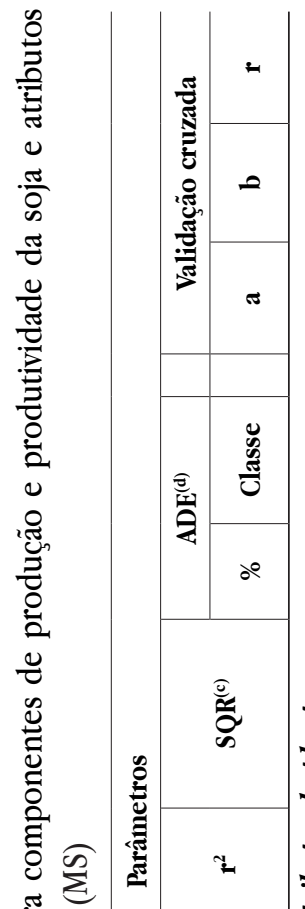

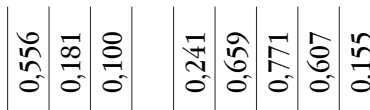

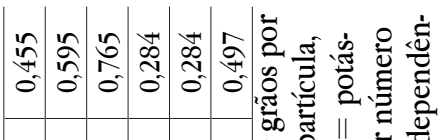

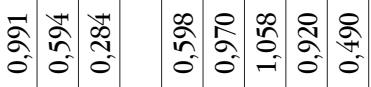

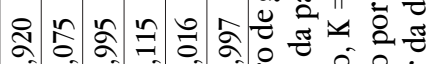

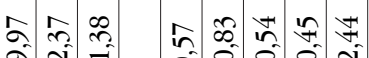

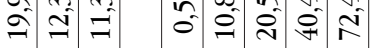

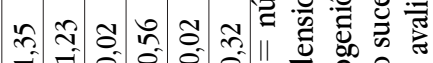

$\because \because 0 \div$ की

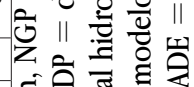

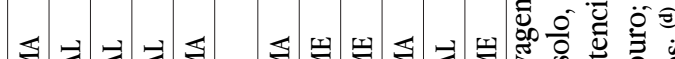

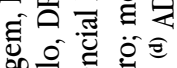

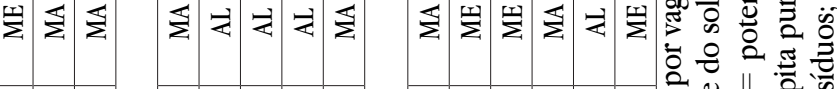

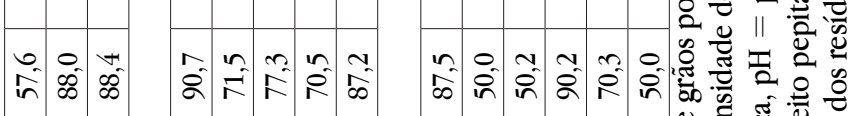

oิ

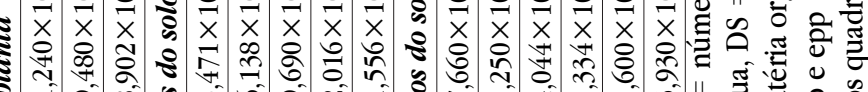

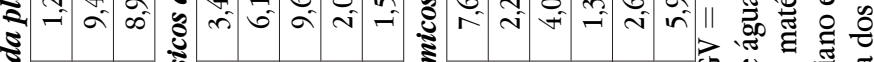

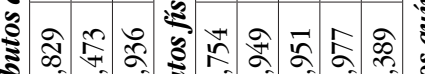

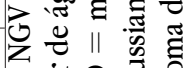

赵

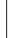

疍

\%

突 気

蛋

空

क 迹

䒿

?

莺

앙

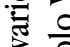

莺

$\infty$

of

\%

욘

突

㺼

i

ำ

.

赵 $=$

0 o 0 - 0

है

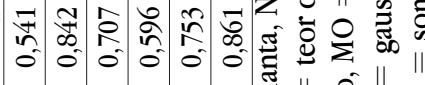

츤 11 잉

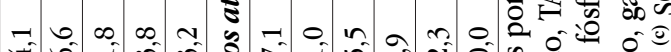

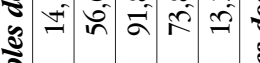

-

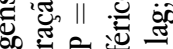

政 政

है

एँ

羊部

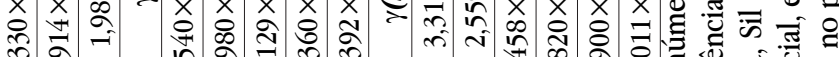

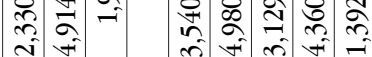

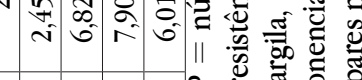

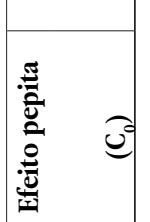

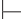

- $\dot{0} \dot{0} \overrightarrow{0}$ ह $\|$ ||

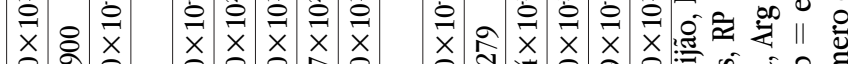

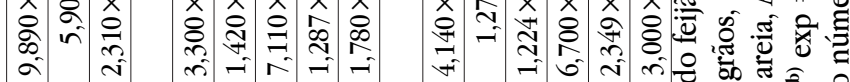

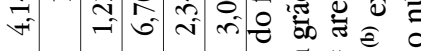
है

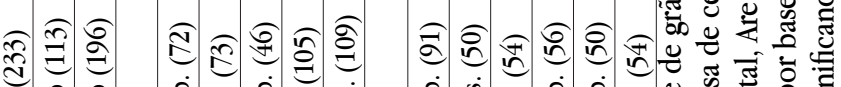
氙

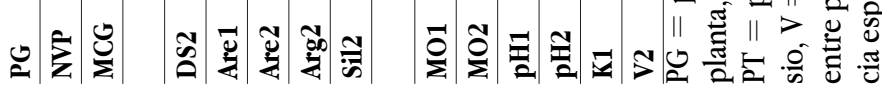


Na Tabela 2 estão apresentados também os parâmetros das validações cruzadas referentes às krigagens da produtividade da soja e dos atributos do solo. Na relação decrescente delas, analisada pela grandeza do coeficiente de correlação (r) obteve os principais atributos: Are2, pH1 e o Are1 como as três melhores validações cruzadas estabelecidas para os atributos, cujos coeficientes de correlação variaram de 0,771 a 0,659 . Tais atributos foram ranqueados aleatoriamente, apresentando uma sequência relativamente semelhante que aquela estabelecida para a grandeza decrescente dos seus alcances, estabelecidos no Quadro II.

Nas Figuras II e III estão apresentados os mapas de krigagem da produtividade da soja e de alguns atributos físicos e químicos do solo. Assim, na Figura IIa, observa-se o mapa de krigagem da PG que apresentou seu maior valor (1.394 $\mathrm{kg} \mathrm{ha}^{-1}$ ) localizados na região Sudoeste, Norte, parte da região Sul, Nordeste e Leste do mapa. Para as demais regiões, tal produtividade de grãos variou entre 972-550 kg ha-1.

Em relação aos atributos do solo, foi notada uma elevada semelhança espacial entre os atributos Are1, Are2, Arg2 e V2, onde os menores valores da Are1, Are2 e Arg2 localizados nas regiões Noroeste, Norte e Nordeste foram o que representaram os maiores valores de V2 $(38,6)$. 


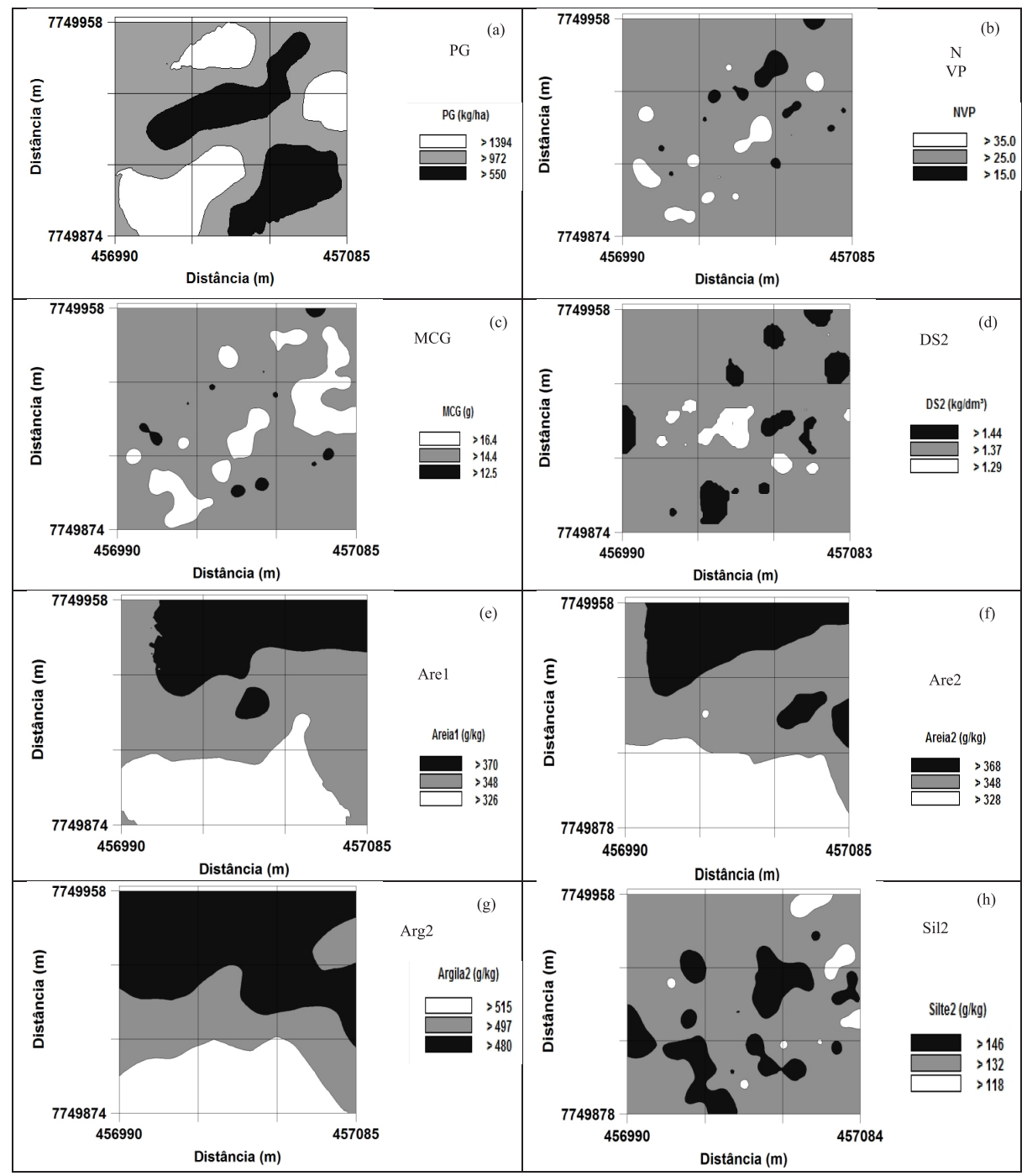

Figura 2. Mapas de krigagem da PG, NVP, MCG, DS2, Are1, Are2, Arg2 e Sil2 da produtividade de um Latossolo Vermelho Distroférrico sob plantio direto, Selvíria (MS) 


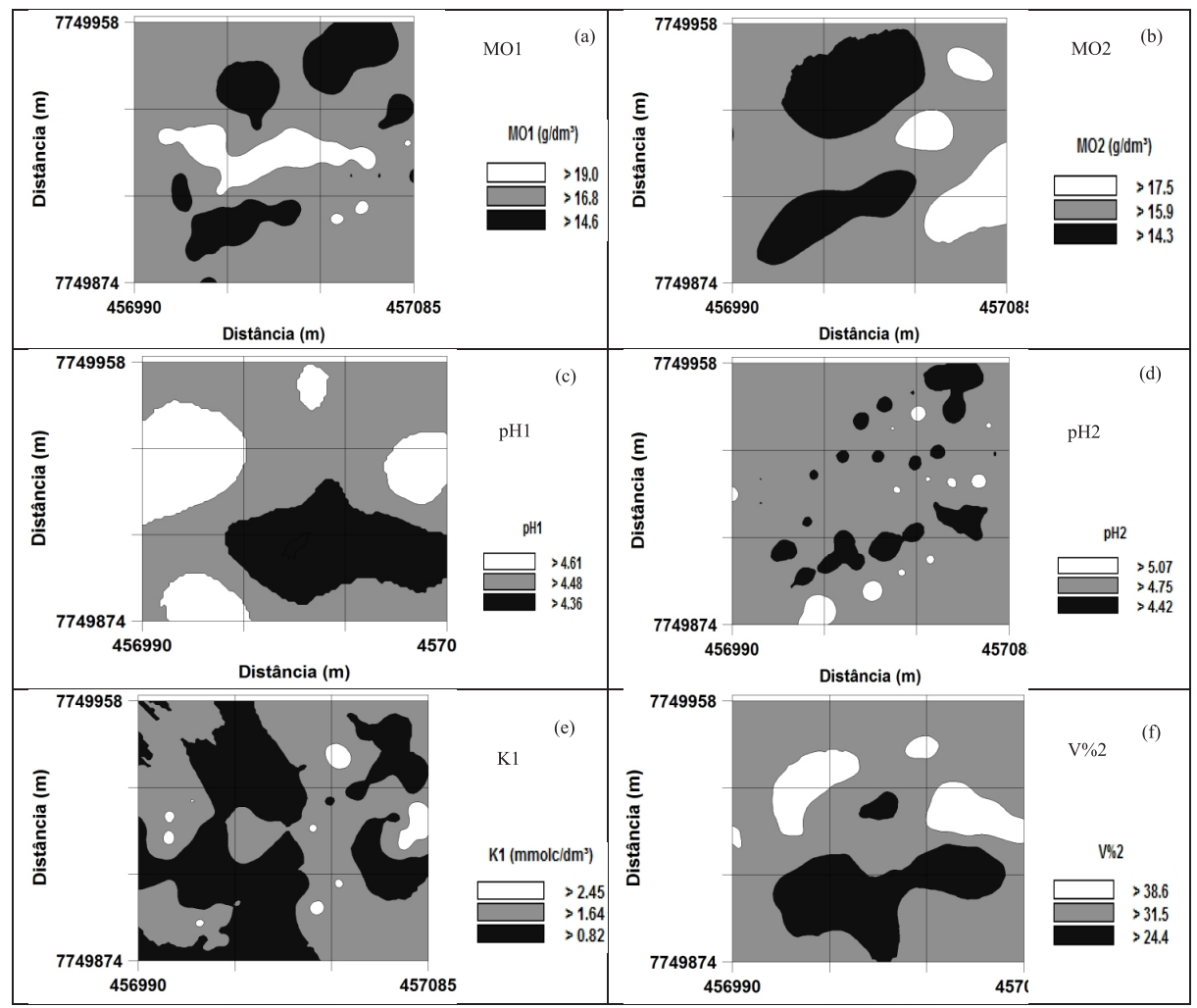

Figura 3. Mapas de krigagem dos atributos (MO1, MO2, pH1, pH2, K1 e V2) de um Latossolo Vermelho Distroférrico sob plantio direto, Selvíria (MS)

\section{DISCUSSÃO}

A alta variabilidade da PG da soja (Quadro I) foi devido a concentrações mais elevadas de nutrientes, água, compactação em algumas partes da área do presente estudo. Diversos autores estudaram a variabilidade da PG em Latossolo Vermelho distroférrico, como Rosa Filho et al. (2009), onde os valores encontrados foram diferentes dos valores observados para a cultura da soja, em plantio direto, Vieira et al. (2010), por sua vez, encontraram média e alta variabilidade de 13,7 e 26,8\% respectivamente e Dalchiavon et al. (2011), também sob plantio direto, encontraram alta variabilidade para NVP (25\%) e NGP $(25,2 \%)$ e baixa para NGV $(8,6 \%)$. A pro- 
dutividade da soja apresenta grande variabilidade de acordo com o comportamento das propriedades físicas e químicas do solo, além da água disponível no solo e quantidade de matéria orgânica, fatores importantes de análise para o planejamento e a avaliação de experimentos e de lavouras comerciais (MATTIONI et al., 2011).

Os valores de DS observados na presente pesquisa concordam com aqueles obtidos por Silva e Lima (2013), em um experimento conduzido em Latossolo Vermelho Amarelo com 100 pontos amostrais, os autores observaram baixa variabilidade para a DS, com CV's entre 5,07 a 7,97\%. Em adição, Silva e Lima (2013) encontraram também baixa variabilidade para Arg, com CV de 9,19\%. Segundo Camargo et al. (2008), o coeficiente de variação permite comparar a variabilidade entre amostras de variáveis com unidades diferentes, porém não permite analisar a variabilidade espacial dos atributos do solo nem seu padrão espacial. A Are e a Arg, por serem atributos não influenciados pelas práticas de manejo da cultura e por apresentarem uma estabilidade maior ao longo tempo, pode-se dizer que a variabilidade que apresentam é intrínseca, ou seja, é devida à variação natural no solo (MONTEZANO et al., 2006), sendo a área avaliada pequena o suficiente para não ocorrerem altas variabilidades.

Os valores de $\mathrm{pH}$ do solo observados no presente estudo concordam com aqueles encontrados por Santos et al. (2014), onde tiveram por objetivo descrever a variabilidade espacial de atributos relacionados à acidez $(\mathrm{pH}, \mathrm{H}+\mathrm{Al}, \mathrm{Al}, \mathrm{Ca}$ e $\mathrm{Mg}$ ) estudando um Latossolo Amarelo Distrófico com pontos amostrais espaçados 5,6 m, encontraram também baixa variabilidade, com CV de 6,1\%.

A resistência a penetração (RP) apresentou variabilidade muito alta e alta, com CV's de 40,4-25,5\%, para as camadas C1 e C2, respectivamente (Quadro I). Assim os valores observados de RP concordam com aqueles obtidos em Argissolo Amarelo e Latossolo Vermelho Distroférrico nas culturas de soja e cana-de-açúcar (RODRIGUES et al., 2014; OLIVEIRA FILHO et al., 2015), que variaram entre 22,1 e 64\%. Os altos valores são efeito da compactação na área que está associada ao tráfego de implementos agrícolas e ao crescimento radicular que aproximam as partículas do solo, os ciclos de umedecimento e secagem conferiram a expansão e contração da massa do solo. Também, a alta variabilidade no solo se deve a RP, quando realizada no local, ocorre a possibilidade de interferência de diversos fatores, como pedras e 
diferenças de umidade devido ao horário de amostragem, por ser um atributo sensível a estas variações.

Para caracterizar o solo química e fisicamente bem como verificar possíveis zonas de manejo em área de cana-de-açúcar e citrus, Miqueloni et al. (2015), trabalhando em um Latossolo Vermelho-Amarelo com 129 pontos amostrais, observaram CV para Sil e MO de 50,56 e 24,27\% respectivamente. Os mesmos autores atribuem tal variação devido a essas camadas sofrerem maiores alterações, principalmente pela ação antrópica, o que acarreta baixo grau de homogeneidade de suas características químicas, principalmente pelo aporte de nutrientes.

Para o P na camada C1, discorda daquele obtido por Negreiros Neto et al. (2014), que estudando em um Latossolo Vermelho-Amarelo em uma malha de 130 $\times 13,5 \mathrm{~m}$, contendo 100 pontos amostrais, encontraram muito alta variabilidade, com $34,37 \%$. Para o K, esses dados concordam com aqueles encontrados por Dalchiavon et al. (2012), que estudando em um Latossolo Vermelho Distroférrico com 120 pontos amostrais em uma área de 3,0 ha, verificaram variabilidade muito alta, com CV's de 51,81 e 59,83\%, respectivamente. A alta variabilidade para os teores de $\mathrm{P}$ e K pode ser atribuída à aplicação localizada de fertilizantes, ao efeito residual da adubação e à exposição de camadas mais deficientes desse nutriente, podendo ocorrer áreas com quantidades excessivas ou com déficit de fertilizantes.

Os atributos TA1, TA2, P1 e V2 apresentaram distribuição de frequência do tipo tendendo a normal com valores de probabilidade associados à estatística do teste Shapiro Wilk (1965) de 0,021, 0,004, 0,023,0,012, e 0,018, respectivamente (Tabela 1). A não normalidade dos dados pode estar atribuída a erros amostrais ou até mesmo a heterogeneidade da área devido ao impacto causado pela mecanização agrícola nas últimas safras, pelas atividades de manejo da cultura e pelos processos de erosão superficial e lixiviação de nutrientes, como era esperado, pois a maioria dos atributos determinados no solo não apresentam ajuste a uma distribuição normal (MONTEZANO et al., 2006). A distribuição de frequência para os demais atributos foi indeterminada (Tabela 1). Verificando os valores indeterminados semelhantes para P2, MO1, MO2, pH1, pH2 e K2, Dalchiavon et al. (2012) obtiveram seus coeficientes de assimetria variando entre 0,126 a 1,632 e de curtose entre -0,323 e 2,071.

$O$ valor médio da PG foi de $1.214,8 \mathrm{~kg} \mathrm{ha}^{-1}$ (Tabela 1), ficando distantes daqueles obtidos por Girardello et al. (2014), que obtiveram uma produtividade de 
$3.630 \mathrm{~kg} \mathrm{ha}^{-1}$. Assim, na presente pesquisa, a média ficou 198,8\% abaixo da produtividade encontrada pelo referido autor, 136,6\% abaixo da produtividade média de SP que foi de $2.874 \mathrm{~kg} \mathrm{ha}^{-1}, 146,4 \%$ abaixo da produtividade brasileira e mundial (CONAB, 2015). A baixa produtividade de soja, neste estudo, foi explicada pela baixa precipitação pluvial durante o ciclo da cultura (Figura 1) e pela elevada compactação do solo (Tabela 1), apresentando menor difusão e absorção de P pela planta, que foi responsável pelo abortamento de vagens e grãos (GRANT et al., 2001), além do período de tempo de adoção do SPD, onde nos últimos anos de cultivo não houve rotação de culturas para melhoria deste sistema, por isso houve redução na qualidade física e química do solo.

Já os atributos componentes de produção de dados pelo número de vagens por planta (NVP), número de grãos por vagem (NGV), número de grãos por planta (NGP) e a massa de cem grãos (MCG) apresentaram os seguintes valores médios: a) NVP (30,5), b) NGV (1,9), c) NGP $(59,1)$ e d) MCG $(15,9$ g) (Tabela 1). Esses resultados obtidos discordam daqueles obtidos por Dalchiavon et al. (2011), que verificaram valores superiores para NVP $(72,2), \operatorname{NGV}(2,2)$ e NGP $(157,6)$, e inferior para MCG $(14,4)$. Esta diferença pode ocorrer também devido a fatores pluviométricos ocorridos no ano, ou também a compactação, que causa uma redução na capacidade das raízes crescerem em profundidade, reduzindo a absorção de nutrientes.

Os valores médios da RP, TA, DS, PT, Are, Arg e Sil diferiram dos dados daqueles obtidos por Faraco et al. (2008), que trabalhando em um Latossolo Vermelho Distroférrico com 100 pontos amostrais em sistema de plantio direto, encontraram DS1, DS2, RP1, RP2, TA1 e TA2 com valores de 1,101; 1,118; 2,729; 2,427; 0,369 e 0,391 respectivamente (Quadro I). Trabalhando em um Latossolo Vermelho Distroférrico sob semeadura direta com 103 pontos amostrais, Souza et al. (2001) encontraram valores semelhantes para PT e TA, que foi de 0,$46 ; 0,44 \mathrm{~m}^{3} \mathrm{~m}^{-3}$ e 0,$17 ; 0,17 \mathrm{~kg}$ $\mathrm{kg}^{-1}$ respectivamente. Os valores de PT ficaram próximos do solo considerado ideal, do ponto de vista agronômico, que é o que apresenta $0,50 \mathrm{~m}^{3} \mathrm{~m}^{-3}$ de porosidade total, conforme preceitos de Kiehl (1979).

Os dados de RP2 concordam com aqueles observados de Dalchiavon et al. (2012), onde encontraram valores normais para os atributos, que apresentou coeficientes de assimetria de 0,262 e curtose de 0,168. Valores normais para RP2, 
DS1 e DS2 com coeficientes de assimetria e curtose variando entre -0,608 a 0,226 foram verificados por Rosa Filho et al. (2009).

Ocorreu um aumento das DSs e RPs e diminuição das PTs conforme o aumento da profundidade. As camadas encontravam-se compactadas, tornando-se um fator limitante para máxima expressão da produtividade da soja, prejudicada tanto pelo deficiente crescimento radicular, assim como pelas consequentes deficiências proporcionadas à absorção nutricional. Na camada $\mathrm{C} 2$ ocorreu maior acúmulo de água no solo, devido ao caminhamento da argila para camadas mais profundas, consequentemente o menor conteúdo de água no solo ocorre menor compactação, por causa das partículas que se aglutinam por forças de coesão, formando agregados mais resistentes, que impedem o deslocamento das partículas e seu rearranjamento e consequente compactação do solo (BEUTLER et al., 2005).

Trabalhando em um Latossolo Vermelho distroférrico sob plantio direto com 64 pontos amostrais, Cavalcante et al. (2007) encontraram para $\mathrm{pH}$ ( $\mathrm{pH} 1 \mathrm{de}$ 5,3 e pH2 de 4,9), K (K1 de 4,6 mmolc dm ${ }^{-3}$ e K2 de 1,8 mmolc dm m $^{-3}$ e V (V1 de 68,5 e V2 de 54,7\%), diferindo dos da presente pesquisa. Trabalhando em um Latossolo Vermelho-Escuro sob diferentes manejos, Souza e Alves (2003) diferiram para os atributos $\mathrm{P}$ e $\mathrm{K}$ em plantio direto, que encontraram valores em profundidade de 30,0; $14,6 \mathrm{mg} \mathrm{dm}^{-3}$ e 5,31; 2,63 $\mathrm{mmol}_{\mathrm{c}} \mathrm{dm}^{-3}$, respectivamente.

Em relação ao Arg2, o valor do $\mathrm{R}^{2}(0,977)$ indicou ser o atributo de melhor ajuste semivariográfico, concordando com aqueles observados por Souza et al. (2004), quando trabalhando em um Latossolo Vermelho eutroférrico sob cultivo de cana-de-açúcar, obtiveram o valor de 0,99 . Em relação ao ADE, a moderada dependência verificada $(\mathrm{ADE}=70,5 \%)$ e o modelo esférico modelado também concordam com o referido autor, no qual o ADE observado foi de 68\% (Tabela 2).

A grande variabilidade dos dados revelou os problemas que podem ocorrer quando se usa a média dos valores dos atributos como base para a tomada de decisão sobre a realização do manejo químico do solo no sulco de semeadura. Em alguns locais, a dose recomendada de fertilizantes ou corretivos pode ser subdimensionada; em outros, será adequada e, em outros, poderá haver aplicação excessiva de determinado fertilizante ou corretivo. Isto resulta em prejuízos econômicos, tanto pela aplicação desnecessária de fertilizantes e defensivos, quanto pelo desequilí- 
brio entre as quantidades de nutrientes que serão disponibilizados para as plantas, além do efeito deletério que essa prática pode ocasionar sobre o meio ambiente (CORÁ et al., 2004).

Práticas de manejo inadequados como a adoção do cultivo intensivo, em vez do cultivo mínimo ou do plantio direto, podem levar à queda rápida do teor de matéria orgânica do solo, pois esta estabiliza e agrega as partículas do solo, melhorando o armazenamento e o fluxo de água, mantendo os solos menos compactados, em adição, retém o C da atmosfera e nutrientes como Ca, Mg e K (NOVAES et al., 2007). Manter e aumentar o teor de matéria orgânica do solo são condições primordiais para evitar a diminuição da fertilidade dos solos e para garantir a sua qualidade e o seu pleno funcionamento nos agrossistemas produtivos.

Para o segundo (Are2), seu valor do $\mathrm{r}^{2}(0,951)$, que indicou ser o segundo atributo de melhor ajuste semivariográfico, discordando com aquele verificado por Amaro Filho et al. (2007), no qual foi de 0,429 . Em relação ao ADE, o forte valor verificado (77,3\%) concordou com Amaro Filho et al. (2007), no qual foi de $100 \%$. O modelo exponencial ajustado para o Are2 discorda dos observados pelos referidos autores, que encontraram modelo Linear. Também, o alcance do Are2 do presente $(91,8 \mathrm{~m})$ foi semelhante aos encontrados por Amaro Filho et al. (2007), que foi de 93,54 m (Tabela 2).

Pode-se ressaltar que o atributo Are2 apresentou o terceiro coeficiente de determinação espacial $\left(\mathrm{r}^{2}\right)$ e também o maior coeficiente de correlação (r) para a validação cruzada. Dessa forma, quando do ponto de vista da análise geoestatística, o Are2 apresentou-se como um plausível indicador da qualidade física do solo.

De uma maneira geral, a variabilidade espacial dos atributos do solo indicou resultados com teores variando desde a classe baixa até a classe alta. Por outro lado, o teor de MO, o qual é atributo que afeta a disponibilidade de nutrientes às culturas e a capacidade de troca de cátions, além da melhoria nos atributos físicos, estavam abaixo daqueles descritos por Raij et al. (2011), sendo representado em toda a malha experimental. No entanto, a elevada acidez $(4,36<\mathrm{pH}<5,07)$ e a baixa saturação por bases $(\mathrm{V}<40,0 \%)$, evidenciaram a necessidade de realização de calagem na área, onde os maiores valores dos referidos atributos conferiram maior PG da soja (Figura 2 e 3), com o objetivo de homogeneizar a fertilidade do solo, de maneira que as culturas agrícolas possam responder satisfatoriamente em produtividade. 


\section{CONSIDERAÇÕES FINAIS}

A baixa produtividade de grãos da soja está associada pela elevada compactação do solo e pela baixa precipitação pluvial durante o ciclo da cultura, apresentando menor difusão e absorção de P pela planta, que foi responsável pelo abortamento de vagens e grãos, conferindo a baixa produtividade de grãos de soja.

A elevada acidez e a baixa saturação por bases evidenciaram a necessidade de realização de calagem na área, onde os maiores valores dos referidos atributos conferiram maior PG da soja.

Visando auxiliar trabalhos voltados à agricultura de precisão, os quais venham a utilizar atributos semelhantes que os do presente estudo, os valores dos alcances da dependência espacial a serem empregados deverão estar compreendidos entre 9,9 e $91,8 \mathrm{~m}$.

Os mapas de krigagem confeccionados permitiram visualizar a distribuição dos atributos físicos e químicos estudados e a influência nos parâmetros de produtividade da soja cultivada em Selvíria (MS), tornando uma importante ferramenta para o planejamento da produção dessas áreas.

\section{AGRADECIMENTOS}

Aos Primeiros Projetos-FUNDUNESP processo número: 0235/001/14-PRO$\mathrm{Pe} / \mathrm{CDC}$ pelo apoio financeiro.

\section{REFERÊNCIAS}

AMARO FILHO, J.; RONNIE NEGREIROS, R. F. D.; ASSIS JÚNIOR, R. N.; MOTA, J. C. A. Amostragem e variabilidade espacial de atributos físicos de um Latossolo vermelho em Mossoró, RN. R. Bras Ci Solo, Viçosa, v. 31, p. 415-22, 2007.

BEUTLER, N. A.; CENTURION, J. F.; ROQUE, C. G.; FERRAZ, M. V. Densidade relativa ótima de Latossolos vermelhos para a produtividade de soja. R. Bras Ci Solo, Viçosa, v. 29, p. 843-49, 2005. 
CAMARGO, L. A.; MARQUES JÚNIOR, J.; PEREIRA, G. T.; HORVAT, R. A. Variabilidade espacial de atributos mineralógicos de um Latossolo sob diferentes formas do relevo. II - Correlação espacial entre mineralogia e agregados. R. Bras. Ci. Solo, Viçosa. v. 32, p. 2279-2288, 2008.

CASTRIGNANÒ, A.; GIUGLIARINI, L.; RISALITI, R.; MARTINELLI, N. Study of spatial relationships among some soil physico-chemical properties of a field in central Italy using multivariate geostatistics. Geoderma, v. 97, p. 39-60, 2000.

CAVALCANTE, E. G. S.; ALVES, M. C.; SOUZA, Z. M.; PEREIRA, G. T. Variabilidade espacial de atributos químicos do solo sob diferentes usos e manejos. R. Bras Ci Solo, Viçosa, v. 31, p. 1329-39, 2007.

COMPANHIA NACIONAL DE ABASTECIMENTO - CONAB. Acompanhamento da safra brasileira: grãos, v. 2 - Safra 2014/15, n. 8 - Oitavo levantamento, Brasília, p. 1-118, maio 2015.

CORÁ, J. E.; ARAÚJO, A. V.; PEREIRA, G. T.; BERALDO, J. M. G. Variabilidade espacial de atributos do solo para adoção do sistema de agricultura de precisão na cultura de cana-de-açúcar. R. Bras Ci Solo, Viçosa, v. 28, p. 1013-21, 2004.

DALCHIAVON, F. C.; CARVALHO, M. P.; FREDDI, O. S.; ANDREOTTI, M.; MONTANARI, R. Variabilidade espacial da produtividade do feijoeiro correlacionada com atributos químicos de um Latossolo Vermelho distroférrico sob sistema de semeadura direta. Bragantia, Campinas, v. 70, p. 908-16, 2011.

DALCHIAVON, F. C.; CARVALHO, M. P.; ANDREOTTI, M.; MONTANARI, R. Variabilidade espacial de atributos da fertilidade de um Latossolo Vermelho distroférrico sob Sistema Plantio Direto. R Ci Agron, v. 43, p. 453-61, 2012.

EMPRESA BRASILEIRA DE PESQUISA AGROPECUÁRIA - EMBRAPA. Sistema brasileiro de classificação de solos. 3. ed. Rio de Janeiro: 2013.

EMPRESA BRASILEIRA DE PESQUISA AGROPECUÁRIA - EMBRAPA. Evolução e Perspectivas de Desempenho Econômico Associadas com a Produção de Soja nos Contextos Mundial e Brasileiro. Londrina: 2011.

FARACO, M. A.; URIBE-OPAZO, M. A.; SILVA, E. A. A.; JOHANN, J. A.; BORSSOI, J. A. Seleção de modelos de variabilidade espacial para elaboração de mapas temáticos 
de atributos físicos do solo e produtividade da soja. R Bras Ci Solo, Viçosa, v. 32, p. 463-76, 2008.

FREITAS, R. E.; MENDONCA, M. A. A. Expansão Agrícola no Brasil e a Participação da Soja: 20 anos. Rev. Econ. Sociol. Rural, Brasília, v. 54, p. 497-516, 2016.

GAMMA DESIGN SOFTWARE: GS + . Geostatistics for Environmental Sciences. $7^{\text {th }}$ ed. Michigan, Plainwell: Gamma Desing Software, 2004.

GIRARDELlO, V. C.; AMADO, T. J. C.; SANTI, A. L.; CHERUBIN, M. R.; KUNZ, J.; TEIXEIRA, T. G. Resistência à penetração, eficiência de escarificadores mecânicos e produtividade da soja em Latossolo argiloso manejado sob plantio direto de longa duração. R. Bras Ci Solo, Viçosa, v. 38, p. 1234-44, 2014.

GRANT, C. A.; FLATEN, D. N.; TOMASIEWICZ, D. J.; SHEPPARD, S. C. A importância do Fósforo no Desenvolvimento inicial da planta. Informações Agronômicas, v. 95, p. 1-5, 2001.

KIEHL, Z. J. Manual de edafologia. São Paulo: Agronômica Ceres, 1979.

MACHADO, L. O.; LANA, A. M. Q.; LANA, R. M. Q.; GUIMARÃES, E. C.; FERREIRA, C. V. Variabilidade espacial de atributos químicos do solo em áreas sob sistema plantio convencional. Rev. Bras. Ciênc. Solo, Viçosa, v. 31, p. 591-599, 2007.

MATTIONI, N. M.; SCHUCH, L. O. B.; VILLELA, F. A. Variabilidade espacial da produtividade e da qualidade das sementes de soja em um campo de produção. Rev Brasi Sementes, v. 33, p. 608-615, 2011.

MIQUELONI, D. P.; GIANELLO, E. G.; BUENO, C. R. P. Variabilidade espacial de atributos e perda de solo na definição de zonas de manejo. Pesq Agropec Trop., Goiânia, v. 45, p. 18-28, 2015.

MONTANARI, R.; SOUZA, G. S. A.; PEREIRA, G. T.; MARQUES JÚNIOR, J.; SIQUEIRA, D. S.; SIQUEIRA, G. M. The use of scaled semivariograms to plan soil sampling in sugarcane fields. Precision Agricult, v. 35, p. 1234-39, 2012.

MONTANARI, R.; PANACHUKI, E.; LOVERA, L. H.; CORREA, A. R.; OLIVEIRA, I. S.; QUEIROZ, H. A.; TOMAZ, P. K. Variabilidade espacial da produtividade de sorgo e de atributos do solo na região do ecótono Cerrado-Pantanal, MS. R. Bras Ci Solo, 
Viçosa, v. 39, p. 385-96, 2015.

MONTEZANO, Z. F.; CORAZZA, E. J.; MURAOKA, T. Variabilidade espacial da fertilidade do solo em área cultivada e manejada homogeneamente. R. Bras Ci Solo, Viçosa, v. 30, p. 839-47, 2006.

NEGREIROS NETO, J. V.; SANTOS, A. C.; GUARNIERI, A.; SOUZA, D. J. A. T.; DARONCH, D. J.; DOTTO, M. A.; ARAÚJO, A. S. Variabilidade espacial de atributos físico-químicos de um Latossolo Vermelho-Amarelo distrófico em sistema plantio direto. Semina: Ci Agrár, v. 35, p. 193-04, 2014.

NOVAES, R. F.; ALVAREZ, V. H.; BARROS, N. F.; FONTES, R. L. F.; CANTARUTTI, R. B.; NEVES, J. C. L. Fertilidade do solo. Viçosa: Sociedade Brasileira de Ciência do Solo, 2007.

OLIVEIRA FILHO, F. X.; MIRANDA, N. O.; MEDEIROS, J. F.; SILVA, P. C. M.; MESQUITA, F. O.; COSTA, T. K. G. Zona de manejo para preparo do solo na cultura da cana-de-açúcar. R. Bras Eng Agríc Amb, Campina Grande, v. 19, p. 186-93, 2015.

PIMENTEL-GOMES, F.; GARCIA, C. H. Estatística aplicada a experimentos agronômicos e florestais: Exposição com exemplos e orientações para uso de aplicativos. Piracicaba: Fundação Escola de Agricultura Luiz de Queiroz, 2002.

RAIJ, B. V. A. N.; ANDRADE, J. C.; CANTARELLA, H.; QUAGGIO, J. A. Análise química para avaliação da fertilidade de solos tropicais. Campinas: Instituto Agronômico, 2001.

RAIJ, B. V. A. N. Fertilidade do solo e manejo de nutrientes. Piracicaba: Ed. IPNI, 2011. REYNOLDS, W.; DRURY, C. F.; YANG, X. M.; TAN, C. S. Optimal soil physical quality inferred through structural regression and parameter interactions. Geoderma, v. 146, p. 466-74, 2008.

RODRIGUES, M. S.; RAMOS, R. R. D.; AZEVEDO, T. P.; PATROCÍNIO FILHO, A. P.; OLIVEIRA, L. G. Variabilidade espacial da resistência do solo à penetração em área de capineira irrigada no semiárido. Agropec Cient Semi-Árido, Campina Grande, v. 10, p. 161-6, 2014.

ROSA FILHO, G.; CARVALHO, M. P.; ANDREOTTI, M.; MONTANARI, R.; BINOTTI, F. F. S.; GIÓIA, M. T. Variabilidade da produtividade da soja em função de atributos 
físicos de um Latossolo vermelho distroférrico sob plantio direto. R. Bras Ci Solo, Viçosa, v. 33, p. 283-93, 2009.

SANTOS, E. O. J.; GONTIJO, I.; SILVA, M. B. Spatial variability of soil acidity attributes and liming requirement for conilon coffee. Coffee Sci, Lavras, v. 9, p. 275-83, 2014.

SANTOS, H. G.; SÁ, L. A. C. M.; NERO, M. A.; PORTUGAL, J. L. Análise exploratória espacial dos preços das terras agrícolas no estado de São Paulo. Rev. Bras. Geom., Curitiba, v. 3, p. 7-16, 2015.

SHAPIRO, S. S.; WILK, M. B. An analysis of variance test for normality (complete sample). Biometrika, Great Britain, v. 52, p. 591-11, 1965.

SILVA, A. S.; LIMA, J. S. S. Atributos físicos do solo e sua relação espacial com a produtividade do café arábica. Coffee Sci, Lavras, v. 8, p. 395-403, 2013.

SOUZA, Z. M.; SILVA, M. L. S.; GUIMARÃES, G. L.; CAMPOS, D. T. S.; CARVALHO, M. P.; PEREIRA, G. T. Variabilidade espacial de atributos físicos em um Latossolo vermelho distrófico sob semeadura direta em Selvíria (MS). R. Bras Ci Solo, Viçosa, v. 25, p. 699-707, 2001.

SOUZA, Z. M.; ALVES, M. C. Propriedades químicas de um Latossolo vermelho distrófico de cerrado sob diferentes usos e manejos. R. Bras Ci Solo, Viçosa, v. 27, p. 133-9, 2003.

SOUZA, Z. M.; MARQUES JÚNIOR, J.; PEREIRA, G. T.; BARBIERI, D. M. Variabilidade espacial da textura de um Latossolo vermelho eutroférrico sob cultivo de cana-de-açúcar. Eng Agríc., Jaboticabal, v. 24, p. 309-19, 2004.

SPIEGEL, M. R. Estatística. 2. ed. São Paulo: McGraw-Hill do Brasil, 1985.

STOLF, R. Teoria e teste experimental de fórmulas de transformação dos dados de penetrômetro de impacto em resistência do solo. R. Bras Ci Solo, Viçosa, v. 15, p. 229-35, 1991.

VIEIRA, S. R.; GUEDES FILHO, O.; CHIBA, M. K.; MELLIS, E. V.; DECHEN, S. C. F.; MARIA, I. C. Variabilidade espacial dos teores foliares de nutrientes e da produtividade da soja em dois anos de cultivo em um Latossolo vermelho. R. Bras Ci Solo, Viçosa, v. 34, p. 1503-14, 2010. 
Recebido em: 21/06/2017

Aceito em: 24/05/2018 